\title{
Mining bike-sharing travel behavior data: An investigation into trip chains and transition activities
}

\author{
Ying Zhang ${ }^{\mathrm{a}, \mathrm{b}, *}$, M.J.G. Brussel ${ }^{\mathrm{b}}$, Tom Thomas ${ }^{\mathrm{c}}$, M.F.A.M. van Maarseveen ${ }^{\mathrm{b}}$

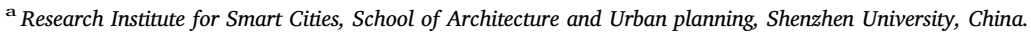 \\ ${ }^{\mathrm{b}}$ Faculty of Geo-Information Science and Earth Observation (ITC), University of Twente, PO Box 217, 7500AE Enschede, The Netherlands \\ ${ }^{\mathrm{c}}$ Centre for Transport studies, University of Twente, PO Box 217, 7500AE Enschede, The Netherlands
}

\section{A R T I C L E I N F O}

\section{Keywords:}

Bike-sharing trips

Trip chains

Transition activity

Travel behavior

Travel purposes

\begin{abstract}
A B S T R A C T
This study aims to explore the travel behavior of bike-sharing users in Zhongshan, China. To this end, we use 5 months of trip data, which included origin and destination locations, and pickup and return time of each used bike in the system. To get a complete picture of the behavior, we distinguished between trips, trip chains, and transition activities. We categorized different trip chains and constructed transition matrices between activities. We found that almost all trips have different origin and destination stations. Two thirds of the trips are part of a trip chain consisting of multiple trips. Although users often use another station to start their next trip, a clear picture emerges in which public bikes are used as a single mode to hop from one destination to another, and at the end return more or less to the same location where the trip chain was started. Moreover, based on the trip chain matrices and transition matrices between activities, we conclude that users mainly used public bikes for commuting, and some of users went home during lunch break, while the system was also used or after-work shopping activities.
\end{abstract}

\section{Introduction}

Bike-sharing programs have increased rapidly over the past decade (Fishman, 2016). One of the main advantages of bike-sharing programs is convenience (Ricci, 2015; Shaheen, Guzman, \& Zhang, 2010). Although it is quite difficult to disentangle several effects that may be responsible for increasing cycling rates, there is evidence that cycling has increased in some cities (e.g. Washington DC, Lyon, Paris, and Barcelona) after bike-sharing programs were introduced, indicating a modal shift from other modes to the public bike (Fishman, Washington, \& Haworth, 2015; Shaheen, Zhang, Martin, \& Guzman, 2011; Wang, Kong, Xie, \& Yin, 2009). Until November 2017, 2075 bike-sharing programs are in operation around the world (Meddin \& DeMaio, 2017).

Bike-sharing systems are often understood as a supplement to other forms of public transport (DeMaio, 2009; Shaheen, Martin, Cohen, \& Finson, 2012; Wang et al., 2009). Based on a review of international programs, this is not always the case. Zhang, Zhang, Duan, and Bryde (2015) indicated that a significant proportion of bike-sharing users use public bikes to complete their entire urban journey in Zhuzhou (a medium sized Chinese city). Referring to Hangzhou's bike-sharing system (the most successful one in China), such system also acted as a competitor to exiting public transport (Shaheen et al., 2011). Evidence from numerous systems has shown that much of the bike-sharing usage has been a substitute for walking and other public transport (BachandMarleau, Lee, \& El-Geneidy, 2012; Bullock, Brereton, \& Bailey, 2017; Fishman, Washington, \& Haworth, 2014; Martin \& Shaheen, 2014; Shaheen et al., 2011). Moreover, researchers also found that some bikesharing users used to cycle their own bicycles and now have shifted to public bicycles (Castillo-Manzano, Castro-Nuño, \& López-Valpuesta, 2015; O'Neil \& Caulfield, 2012; Yang \& Long, 2016).

Previous researches have indicated that the integrated use of public bicycles and other public transport can be affected by the locations of the bike-sharing stations (Jiménez, Nogal, Caulfield, \& Pilla, 2016; Zhao, Wang, \& Deng, 2015) and the condition of other public transport (Yang \& Long, 2016). For example, some systems which mainly either serve the city center (e.g. Dublin's bike-sharing stations located in the city center) or serve the suburban areas (e.g. the system in Jiangning district of Nanjing, China), have shown an integration with other public transport due to users need to commute between the central and suburban areas (Jiménez et al., 2016; Zhao et al., 2015). To improve the integration of the bike-sharing system and other public transport, the development of both systems cannot be treated separately, as cycling

\footnotetext{
* Corresponding author.

E-mail addresses: y.zhang@szu.edu.cn (Y. Zhang),m.j.g.brussel@utwente.nl (M.J.G. Brussel), t.thomas@utwente.nl (T. Thomas), m.f.a.m.vanmaarseveen@utwente.nl (M.F.A.M. van Maarseveen).
} 
and public transport are complementary to each other (Kager, Bertolini, \& Te Brommelstroet, 2016).

Bike-sharing usage data enable researchers and planners to explore travel behavior on a continuous, large scale, and in a non-invasive way (Beecham \& Wood, 2014). To gain insights into the characteristics and patterns of bike-sharing trips, previous studies either focused on trip characteristics in terms of travel speed and time (Jäppinen, Toivonen, \& Salonen, 2013; Jensen, Rouquier, Ovtracht, \& Robardet, 2010) and the usage types of bike-sharing trips (Bordagaray, Dell'Olio, Fonzone, \& Ibeas, 2016), or focused on employing visualization techniques to explore the gendered travel behavior (Beecham \& Wood, 2014; Zhao et al., 2015), spatial structure of bike-sharing trips (Zaltz Austwick, O'Brien, Strano, \& Viana, 2013) and commuting dynamics (Oliveira, Sotomayor, Torchelsen, Silva, \& Comba, 2016). Those studies can generally be summarized as movement-based research, without considering the transition activities between consecutive trips within a trip chain. Mining the travel behavior and patterns of bike-sharing usage solely depending on the individual trips (i.e. origin and destination) could be biased, as the sequence of activities also provides information on the mobility patterns (Wu, Zhi, Sui, \& Liu, 2014). Moreover, previous studies mainly emphasized the strong origin-destination pairs and patterns, without incorporating the geographical and time information relating to the start and end of the trips. However, the location and time relating to the origin and destination of individual trips are essential for understanding the travel behavior (purpose) of bike-sharing usage.

Within this context, this paper aims to explore the travel behavior of bike-sharing users based on the information extracted from the trip data of bike-sharing users. Moreover, the locational and time information relating to the bike-sharing usage are considered in this study. This study was conducted for a bike-sharing system in Zhongshan (China), using 5 months of trip data from February 2014 to June 2014. This paper only focuses on the weekday bike-sharing usage.

The remainder of this paper is organized as follows: Section 2 presents previous work on travel behavior of bike-sharing usage, Section 3 introduces the transport condition and bike-sharing system in the study area, Section 4 explains the data of bike-sharing usage and methods of this study, Section 5 presents and discusses the results, and Section 6 concludes the paper.

\section{Literature review of bike-sharing usage}

Numerous and various studies have investigated the travel characteristics of bike-sharing users, which shed light on the usage and the role of such systems within different urban backgrounds. Previous researches can be generally classified into three categories: (1) user survey-based studies; (2) station-based studies; and (3) trip-based studies.

\subsection{User survey-based studies}

User survey-based studies were done through interviews and questionnaire surveys on a sample of bike-sharing users, to understand users' profile, perceptions and travel behavior. Referring to travel behavior, several findings were observed. Firstly, many studies have found that bike-sharing trips are mainly substitutes for walking and buses, rather than for private vehicle use (Bullock et al., 2017; Murphy \& Usher, 2015; O'Neil \& Caulfield, 2012; Shaheen et al., 2011; Tang, Pan, \& Shen, 2011). The primary mode (walking or public transport) that is replaced by a bike-sharing system is different in different cities. For example, $85 \%$ of Dublin's bike-sharing users (respondents) substitute bike-sharing for walking (54\%) and public transport (31\%) (O'Neil \& Caulfield, 2012). Tang et al. (2011) indicated that $22.73 \%$ and $34.42 \%$ of Beijing's bike-sharing trips shift from walking and public buses, and $26.15 \%$ and $40.37 \%$ of Shanghai's bike-sharing trips shift from walking and public buses respectively. About $80 \%$ of Hangzhou's bike-sharing users (respondents) shifted from public transport to bicycle use
(Shaheen et al., 2011). Secondly, although users used public bikes for both transport and recreational activities, the most common bikesharing travel purpose is work-related and school-related (Shaheen et al., 2012; Zhang et al., 2015). Thirdly, bike-sharing systems are not consistent in acting as a feeder mode to existing public transport. The role of bike-sharing systems can vary between different cities. Referring to American and European cities, Martin and Shaheen (2014) stated that Washington DC's bike-sharing system led to a fall in public transport use (bus and rail) in the dense central urban area, but increased the public transport use in suburban areas, due to the fact that trips are shorter and that there are more stations in the central urban area and that bike-sharing trips can aid rail ridership in the suburban areas where trips are longer. Fishman, Washington, Haworth, and Mazzei (2014) found that Melbourne's system was potentially substituting for public transit rather than connecting to it. Nikitas, Wallgren, and Rexfelt (2016) indicated that Gothenburg bike-sharing system is a good travel alternative to a car for inner-city trips. Jiménez et al. (2016) suggested that Dublin's bike-sharing system, which is mainly restricted to central urban areas, can be used as a complement to other public transport due to many commuters arriving in the city core by other public transport (bus, tram, train). Referring to the Chinese bikesharing systems, Shaheen et al. (2011) indicated that Hangzhou's bikesharing system, which covers the whole urban area, acted as both a competitor and a complement to the existing public transit. For the bike-sharing system in Jiangning district, which is a suburb area of Nanjing, Zhao et al. (2015) indicated that many trips were connecting with rail, and public bikes also serve as alternatives for moderate-distance trips in such areas. In the city of Zhuzhou (a medium-sized city in China), Zhang et al. (2015) indicated that a significant proportion of users choose public bikes to complete their entire urban trip. An important fact is that most Chinese systems provide a one-hour free of charge time, which is enough for most single trips (Tang et al., 2011).

\subsection{Station-based analyses}

Station-based analyses mainly aim at exploring the usage pattern of bike stations. Some studies have examined the patterns of usage activities at bike stations and have classified stations into several clusters (Jiménez et al., 2016; Kaltenbrunner, Meza, Grivolla, Codina, \& Banchs, 2010; O'Neil \& Caulfield, 2012; Vogel, Greiser, \& Mattfeld, 2011). For example, Vienna's bike-sharing stations are grouped into five clusters according to the pickup and return at each station in the daily course of working days (Vogel et al., 2011), and Dublin's bike stations are grouped into three clusters in terms of generator stations, attractor stations and balanced stations (Jiménez et al., 2016). Some studies have examined the effect of surrounding built environment on the demand at bike stations. They generally found that population and job density, the proximity to metro and public bus stations, bike lanes and points of interests (retail shops, restaurants, parks, etc.) are positively associated with the demand at stations (El-Assi, Salah Mahmoud, \& Nurul Habib, 2015; Faghih-Imani, Eluru, El-Geneidy, Rabbat, \& Haq, 2014; Gonzalez, Melo-Riquelme, \& de Grange, 2016; Zhang, Thomas, Brussel, \& van Maarseveen, 2017a, 2017b). Moreover, station size and nearby other bike stations within the catchment area also have effects on the demand at stations (El-Assi et al., 2015; Faghih-Imani \& Eluru, 2015; Zhang et al., 2017a, 2017b). Additionally, slope is also a key barrier for station usage, i.e. stations located at higher elevations lead to a redistribution problem due to the fact that few bikes are returned to hilltops (MateoBabiano, Bean, Corcoran, \& Pojani, 2016).

\subsection{Trip-based analyses}

Trip-based analyses give a better insight into the characteristics of individual trips, such as travel speed and duration and trip-based movement which offers much more room for investigating the travel behavior of bike-sharing users. Some studies analyzed the travel speed, 
time and distance of cycling trips. Jensen et al. (2010) found that public bikes compete with the car in terms of speed in downtown Lyon, and Jäppinen et al. (2013) found that the adoption of a bike-sharing system can reduce about $10 \%$ of travel time by public transport in Greater Helsinki, on average by more than $10 \%$. Moreover, Mateo-Babiano et al. (2016) uncovered that distinctive Brisbane's bike-sharing trips show a clear morning and evening peak hours on weekdays and shorter trips on weekends than weekdays.

Apart from this, other trip-based studies explored the movement of bike-sharing trips. Studies on the movement of biking trips mainly focused on visualization techniques. The common idea of these movement analyses is to weight the trips between two stations to emphasize the strong Origin-Destination pairs and patterns. The visualization of trajectories shows the bicycle flow over the urban area, which is often represented by lines with a different thickness. Zaltz Austwick et al. (2013) employed visualization techniques to explore the travel behavior of bike-sharing usage in five different cities. They found that systems show similarity in the distribution of trip displacements and durations. However, they did not incorporate information of trip time and any land-use data of stations. Beecham and Wood (2014) proposed an approach to visualizing the flow of London's bike-sharing trips, and found that women tend to use public bikes at weekends and in areas with cycle routes and/or slower traffic, while men tend to use public bikes for commuting. Similar visual techniques were employed by Zhao et al. (2015) who analyzed Nanjing's bike-sharing trip chain that was divided into two major types - O-O (i.e. trip chain starts from an origin "O" and ends at the same origin "O") and O-D (i.e. trip chain starts from an origin "O" and ends at the destination "D"), and uncovered that women tend to make multiple-circle trips and spend more time on cycling than men on weekdays. However, they neglect one potential problem: the distance between the Origin station (O) of the first trip and final destination station of the last trip (D). It is quite possible that users want to drop off the bikes at the original station, but that such a station is full (no parking slots) so that users have to choose a nearby station to return the bikes. In that case, the O-D type could be the potential O-O type. Bordagaray et al. (2016) classified bike-sharing trips into five usage types in terms of round trips (same origin and destination), bike substitution, and perfectly and non-perfectly symmetrical trips, using trip data of Santander's bike-sharing system. The found that $53.9 \%$ of trips made by registered users and $47 \%$ trips made by casual users belong to non-classified usage types, while two predominant usage types are round trips and perfectly symmetrical trips. Oliveira et al. (2016) designed an interactive visualization system to explore the commuting dynamics of New York's bike-sharing system. They mainly aimed for exploring the station balance over time, i.e. identifying whether the condition of station capacity is full or empty. However, they did not consider the geographical information (e.g. points of interest, land use types) relating to the start and end of the trip, which can be beneficial to identifying the potential trip purpose.

To summarize, the existing trip-based researches mainly focused on the characteristics of cycling movements, but neglected transition activities within the trip chain that might be the driving force underlying cycling movements. Moreover, few studies incorporate both locational and time information relating to the start and end of individual trips and trip chains. A major limitation of the operational usage data is that they do not provide trip purpose, but bike-sharing trips vary based on land uses (Ahillen, Mateo-Babiano, \& Corcoran, 2016; Lathia, Ahmed, \& Capra, 2012; Mateo-Babiano et al., 2016). One cannot understand and predict the travel purpose only based on the trip destination. One also needs to know the origin of the next trip (transition from one trip to another trip) and the time between the previous and next trip (i.e. transition time). This study therefore explores the travel behavior of individual bike-sharing users using trips, trip chains, and transitions between trips. The synthesis of these three aspects provides a complete picture of the travel behavior within the bike-sharing system.
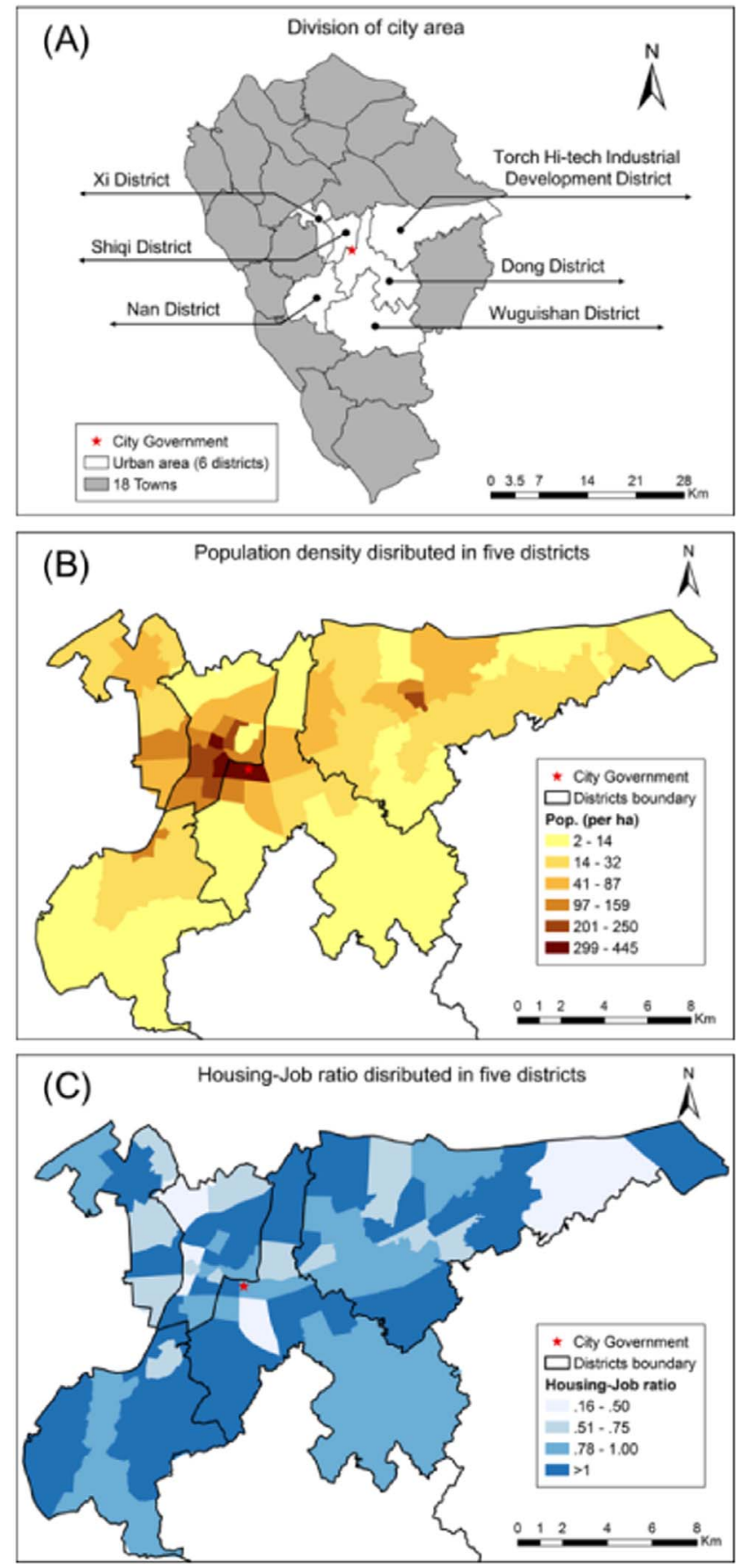

Fig. 1. City background. (A) Division of city area. (B) Population density distributed in study area. (C) Housing-Job ration in study area.

\section{Study area}

\subsection{Transport condition in Zhongshan, China}

Zhongshan city is a prefecture-level city located in the Guangdong province of China. With a total area of $1891.95 \mathrm{~km}^{2}$, the city houses a population of 3.17 million (ZhongshanStatisticsBureau, 2014). As shown in Fig. 1(A), the city government directly administers six districts corresponding to the urban area, and eighteen towns. Moreover, four districts, the Xi, Shiqi, Dong, and Nan districts, constitute the "center urban area" (168.44 km2 with a population of 0.53 million) (ZhongshanStatisticsBureau, 2014). Our study area consists of five districts - Xi, Shiqi, Dong, Nan, and Hi-tech industrial district - with an 

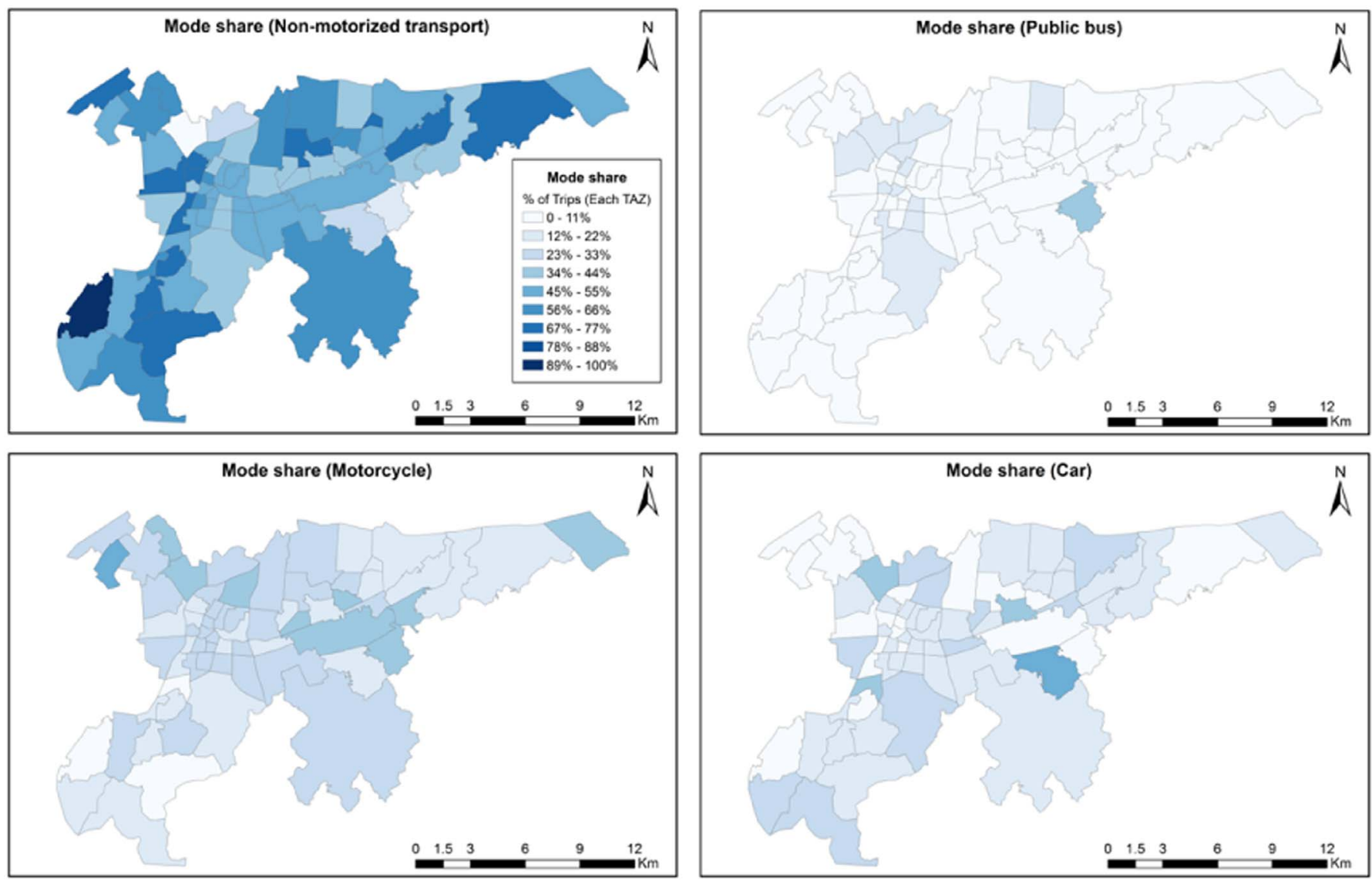

Fig. 2. Modal split of commuting trips in TAZs.

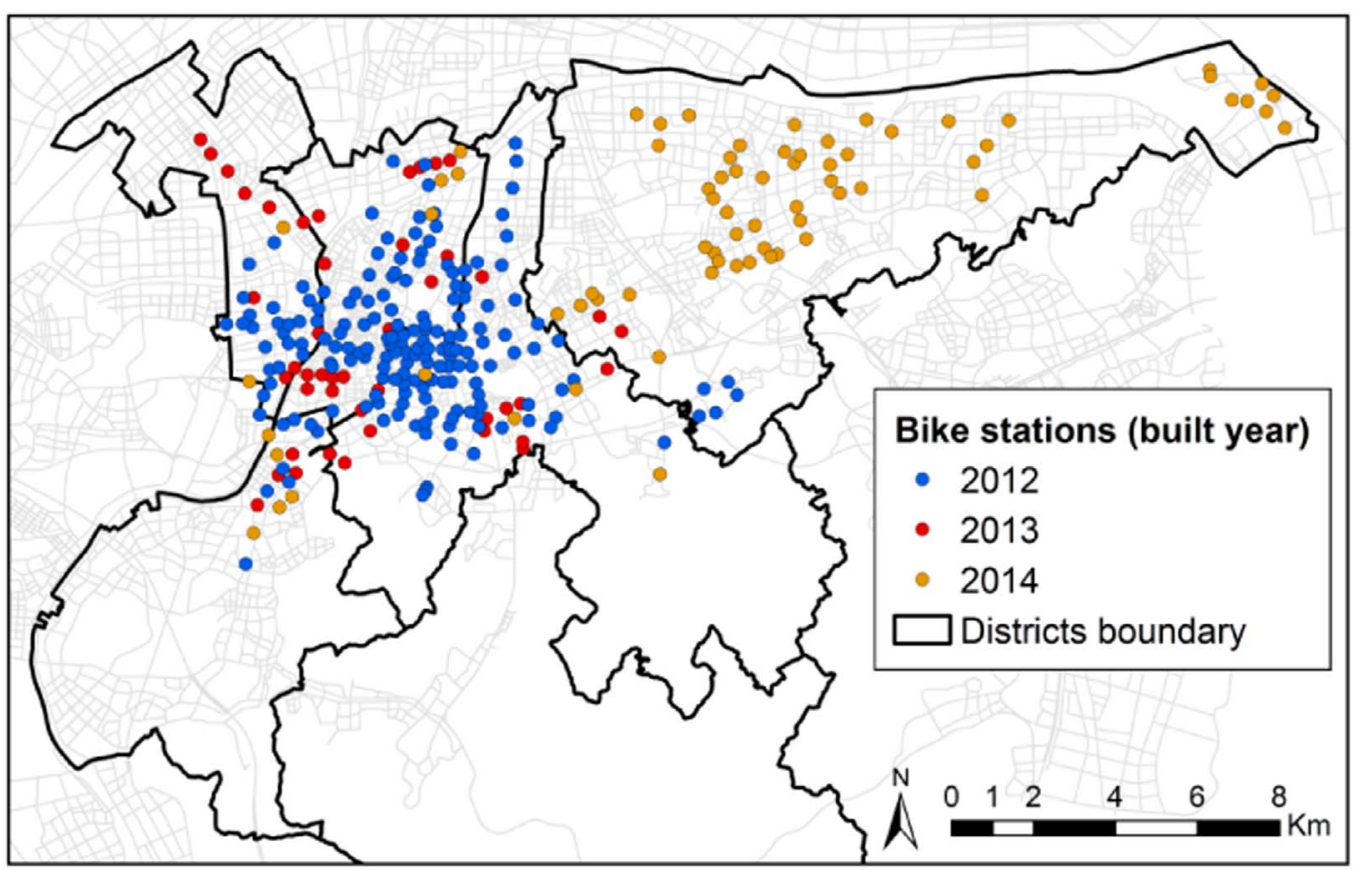

Fig. 3. Spatial distribution of bike stations.

area of $238.44 \mathrm{~km}^{2}$ and a population of 0.77 million (ZhongshanStatisticsBureau, 2014).

Fig. 1(B) and (C) show the distribution of population density and housing-job ratio across the study area respectively. The highest population density is in the "center urban area", and the lowest in the Hitech district. The distribution of Housing-Job ratio across TAZs
(Transport Analysis Zone) was derived from the Zhongshan Household Travel survey in 2010.It indicates that the housing and job are quite comparable in most TAZs.

According to the Zhongshan Household Travel survey in 2010 that was done at the level of the TAZ, the average duration of commuting trips is quite short (less than $20 \mathrm{~min}$ ) in the urban area, irrespective of 
the type of commuting trips. Fig. 2 shows the modal split (four primary modes) in each TAZ. The share of different modes indicates that: nonmotorized $>$ motorcycle $>$ car $>$ public bus. The share of the nonmotorized mode is much larger than that of the public bus. This suggests that commuting by non-motorized transport was the common lifestyle even before running the bike-sharing system, and the public bus is not attractive to citizens neither in the inner area nor on the outer area. In the light of commuting time and modal split, this suggests that local people prefer to commute by walking and biking, and tend to live close to workplaces in general.

\subsection{Zhongshan's bike-sharing system}

Zhongshan's bike-sharing system was launched in 2011 and is a 24/ 7 self-service system. Users can pick up and return public bikes at any station in the course of the day by use of a smart card after membership registration. For each trip, the first hour is free, and the rest of the hours are charged at incremental prices (1CNY per hour), which is quite a lot cheaper than a trip by local public bus ( 2 CNY per trip). The system gradually expanded over the urban area, i.e. from the central urban area to the outer urban areas. Until June 2014, 296 bike stations, equipped with 7855 parking slots were distributed over the urban area. As shown in Fig. 3, 224 of these stations had been built before 2014 and are mainly located in the "center urban area", and 72 bike stations were built in 2014 and are mainly located in "Torch Hi-tech Industrial Development district".

\section{Data and methods}

\subsection{Bike-sharing trip data}

The trip data were provided by the Transport Department of the Urban Planning and Design Institute of Zhongshan (China). The provided trip database consists of usage information from February to June 2014 (five months). Each piece of usage information (i.e. each trip) includes user ID, pickup and return stations, start time and end time of the trip, and trip duration. Moreover, each user ID is unique and connected with the smart card. Referring to the original trip database that records the usage of public bikes from February to June 2014, there are $1,937,265$ records (i.e. trips), generated over the urban area in these five months. Based on data screening, we excluded $6 \%$ of inaccurate records from the original trip database, which included $5.88 \%$ of trips that had a pickup and return at the same station with a duration of less than $1 \mathrm{~min}$, and $0.12 \%$ of trips that had a duration of less than $1 \mathrm{~min}$.

Fig. 4 shows the number of trips originating from each station during the weekday. According to the figure, the centrally located stations show high demands, and outer stations show low demands. Similar results are found for each period of the day (i.e. morning peak hours (MP, 7:00-9:00 a.m.), evening peak hours (EP, 17:00-19:00 p.m.), and off peak hours (rest of hours)). However, there are differences when we compare departures with arrivals. Over a whole day, arrivals and departures are more or less perfectly in balance. When we consider the individual stations there is a correlation of linear relationship between numbers of pickups and returns. When we consider the peak hours, there is more dispersion between the numbers of pickups and returns. In some cases there may be a factor of two or more between the two. However, we do not find a clear geographical pattern in which there are clear morning flows in one direction and evening flows in the opposite direction. This is quite different from other cities (e.g. New York, Montreal (Faghih-Imani \& Eluru, 2016a, 2016b)) that show a distinctive imbalanced trip flow.

\subsection{Research design}

As part of the initial data exploration, we looked at the spatial distribution of O-D bicycle flows, it has several characteristics: (1) bicycle flows are divergent flows from/to a station; (2) there are large numbers of short-distance flows at local scale (TAZ-level); (3) the vast majority of lone flows are thin and crossing each other; (4) there is a high density of stations in the central areas that generated a large amount of trips. In short, the display of the O-D trips eclipses the patterns underneath, the information about the travel patterns and the driving force underlying the bicycle flows cannot be observed explicitly from the current visualization of O-D bicycle flows, i.e. "when, where" those trips occurred.

To explore the travel behavior of bike-sharing users based on the information embedded in the trip data, we examined and synthesized three aspects: (1) bike-sharing trips; (2) trip chains; and (3) transition activities, i.e. transition between trips. Fig. 5 depicts a diagram of a trip chain made by a bike-sharing user, which also incorporates the information of bike-sharing trips and transition activities. The definition of bike-sharing trip chains, trips, and transition activities is as follows:

- A trip chain: a sequence of bike-sharing trips made by the same user within the same day. In this study, we define $24 \mathrm{~h}$ (from 0:00 a.m., all the trips start during these period) as one day, given that the usual daily activity falls within this time period on weekdays. Only for $0.3 \%$ of the trip chains that have trips made during the night

- A bike-sharing trip: a complete trip where a user picks up a public bike from a bike station (origin) and then returns the bike to the same or another station (destination).

- Transition activities: the activity/time between two consecutive bike-sharing trips within a trip chain. Thus, if a trip chain comprises $\mathrm{n}$ number of bike-sharing trips, then there is $\mathrm{n}-1$ number of transition activities within the trip chain.

To examine the patterns of bike-sharing trips, trip chains and transition activities, we used the pickup and return time of bikes per user. Each station was categorized by station type, indicating the main land use type or activity in the direct vicinity of the station. These types are residential (residential communities/buildings), commercial (e.g. shopping malls, markets, office buildings, banks, hotels), institution (government buildings, school/colleges, research institutions, hospitals, etc.), recreation (parks, playgrounds, etc.) and transport (railway stations, inter-city bus stations, public bus terminals/hubs). The type of each bike station is defined by the name and address of the bike station, which follows the principle of site-selection of bike stations in the study area: bike stations are usually named after the nearby residential community, shopping mall, park, institution, etc. Such definition approach also indicates the closest place to bike station. Fig. 6 shows the spatial distribution of bike stations with station type.

To investigate the patterns of trip chains and transition activities, we developed a matrix providing the trips between the start and the end of the trip chain. We call this the trip chain matrix. This matrix indicates when and at which station type the first trip starts and the final trip ends. We also constructed a transition matrix between activities to disclose when and at which station type each user completes one trip and starts the next trip within trip chains. The combination of trip chain and transition activity matrices is an indication of the travel patterns and potential travel purpose of bike-sharing usage. The creation of an individual trip chain was conducted in Python, and the spatial and statistical analyses were operated in ArcGIS and SPSS. The approach of constructing matrices was inspired by Wu et al. (2014) who explored human mobility and activity using social media check-in data.

Consequently, each matrix has 25 large cells ( 5 rows $\times 5$ columns, representing five station types), and each large cell is comprised of 576 small cells ( 24 rows $\times 24$ columns, representing $24 \mathrm{~h}$ ). The data in each small cell represents the number of trip chains (matrix of trip chain) or the number of transition activities (matrix of transition activities). When visualizing the tip chain and transition matrix, we used the Natural Breaks (Jenks) classification method to break the class of values, because this method identifies groups with similar values and 


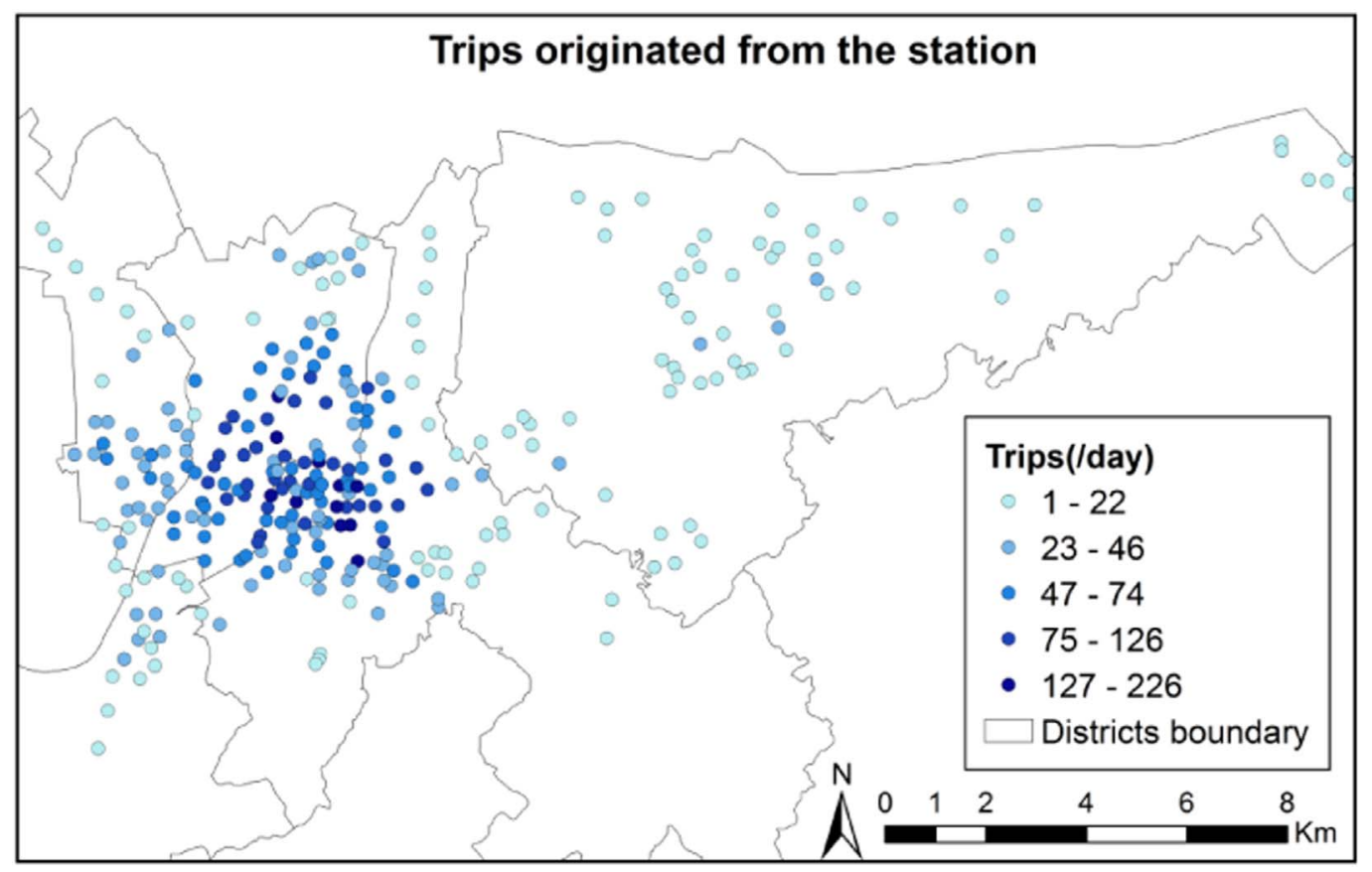

Fig. 4. Bike-sharing trips originating from each station during the weekday.

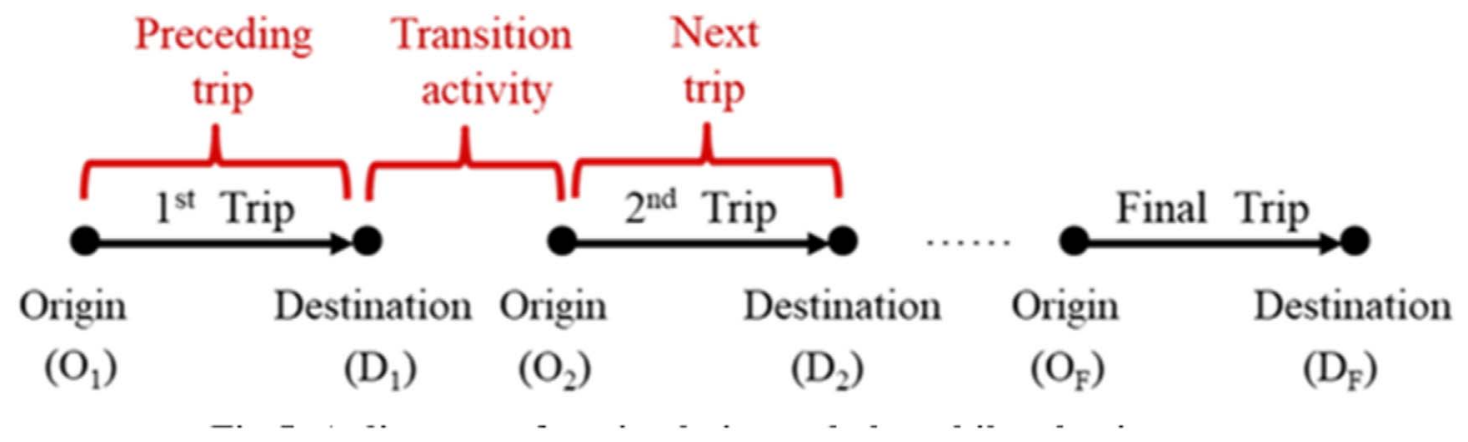

Fig. 5. A diagram of a trip chain made by a bike-sharing user.

maximizes the differences between groups.

\section{Analysis and results}

\subsection{Types of trips, trip chains, and transition activities}

For the transition activities, we firstly examined the interval time between two consecutive trips. We removed trips with interval time between two consecutive trips less than 5 mins ( $78 \%$ of these removed transition activities were less than $1 \mathrm{~min}$ ). Such trips (and transition activities) are likely to be the result of technical issues (e.g. users that are unsatisfied with the bike so they change to another one) rather than genuine activities. Moreover, in these cases we also filtered out the rest of trips made by the same user on the same day ( $7 \%$ of trips and $8 \%$ of trip chains were removed). As a result, we obtained 1,218,244 trips, 334,101 trip chains, and 462,773 transition activities on weekdays.

Table 1 describes the classification of trip data and types of bikesharing trips. The classification of trip data is based on the condition that each individual user makes either one trip per day (TypeI) or multiple trips per day (TypeII). This lays the foundation for exploring trip chains and transition activities. For each type of trip data, each individual trip is classified into two categories: (1) loop trips, a trip starts and ends at the same station; and (2) directional trips, a trip starts from a station but ends at the other station. As shown in Table 1, TypeIIaccounts for $65.4 \%$ of weekday trips. Moreover, compared to loop trips, directional trips make up the vast majority of trips, for both TypeI and TypeII. This indicates that the majority of bike-sharing trips travelled from a station to the other station. The occurrence of loop trips might be associated with recreational activities (physical exercises), or short-time activities (e.g. quick shopping) (Bordagaray et al., 2016).

Based on the trip of TypeII, we can distinguish between loop and non-loop trip chains (respectively TypeII-A and TypeII-B as illustrated in Table 2) and between transfers at the same station (TypeII-C in Table 3) and transfers at different stations (TypeII-D in Table 3). We found that $51.8 \%$ of trip chains belong to loop trip chains (TypeII-A), and $48.2 \%$ of trip chains are non-loop trip chains (TypeII-B). We also found that the majority of transition activities $(62.5 \%)$ refers to TypeII$\mathrm{C}$ and the minority of transition activity (37.5\%) belongs to TypeII-D. To further understand the occurrence of each type of trip chains and transition activities, we investigate the usage patterns in the next section.

\subsection{Patterns of bike-sharing usage}

First, we define four indicators to understand bike-sharing trips: (1) number of trips per trip chain, $N_{\text {trip }}$; (2) the average trip length per trip chain, $\overline{d_{T}}$ (Eq. (1)); (3) the average transfer distance (between station $\mathrm{D}_{\mathrm{P}}$ and station $\mathrm{O}_{\mathrm{N}}$ ) per trip chain, $\overline{d_{D_{p} O_{N}}}$ (Eq. (2)); and (4) the average distance between the destination of the final trip and the origin of the 


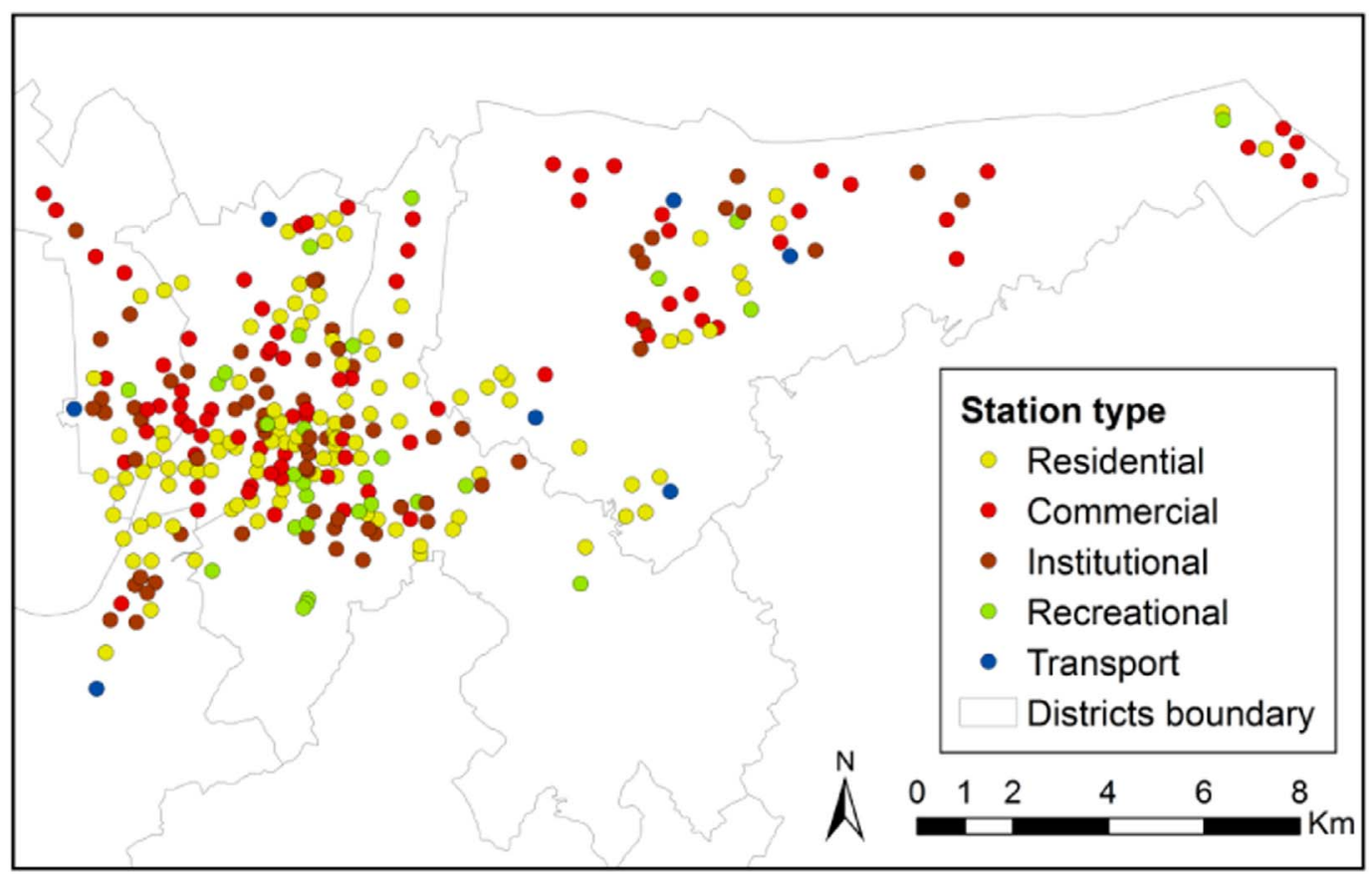

Fig. 6. Spatial distribution of bike stations with corresponding station type.

Table 1

Types of individual bike-sharing trips (weekdays).

\begin{tabular}{lll}
\hline TypeI & User makes one trip per day & Percentage \\
\hline & Loop trips (same start/end station) & $2.7 \%$ \\
& Directional trips & $31.9 \%$ \\
& TypeI total & $34.6 \%$ \\
& & \\
\hline \multirow{2}{*}{ TypeII } & Multiple trips per day & Percentage \\
\hline & Loop trips (same start/end station) & $1.8 \%$ \\
& Directional trips & $63.6 \%$ \\
& TypeII total & $65.4 \%$ \\
\hline
\end{tabular}

first trip per trip chain, $d_{D_{F}} O_{1}$. We conducted Network Analyst analysis in ArcGIS to calculate the shortest network distance between stations along the road network, due to such system is not equipped with GPS to record trajectory data.

$\overline{d_{T}}=\left(\sum_{i=1}^{N_{\text {trip }}} d_{O_{i} D_{i}}\right) / N_{\text {trip }}$

$\overline{d_{D_{P} O_{N}}}=\left(\sum_{i=1}^{N_{\text {trip }}-1} d_{D_{i} O_{i+1}}\right) /\left(N_{\text {trip }}-1\right)$

Fig. 7 shows the relation between pairs of indicators, with each cell representing the number of trip chains. For each single figure (Fig. 7(a), (b), (c)), we use Jenks Natural breaks method to classify the data of cells to identify groups with similar values and maximize the differences between groups. This was done because data points are unevenly distributed within the data domain.

Fig. 7(a) describes the relation between the number of trips per trip chain and the average trip length per trip chain. It illustrates that the majority of trip chains consist of two or three trips and that the most common trip length is less than $1800 \mathrm{~m}$, irrespective of the number of trips per trip chain. However, most trip chains with long trips beyond $3 \mathrm{~km}$, only consist of two trips.

Fig. 7(b) describes the relation between the average transfer distance per trip chain and the average trip length per trip chain. This shows that trip lengths are typically larger than transfer distances. Most common are transfer distances below $600 \mathrm{~m}$, and these distance are rather independent of trip lengths in the chain. This suggests that public bikes are mainly used as the single transport mode, either for short local trips that might substitute for walking (area B), or for a long distance trip (area C). The fact that quite a significant fraction does not transfer to the same station, but to a nearby station, could be explained as follows: (1) station capacity (i.e. number of available bikes or parking slots) is not enough so that users have to shift to a nearby station to pick up or return a bike; (2) users just select one of neighboring stations either randomly or determined by their other activities. In addition, this also suggests that neighboring stations are complementary to each

Table 2

Types of trip chains (weekdays).

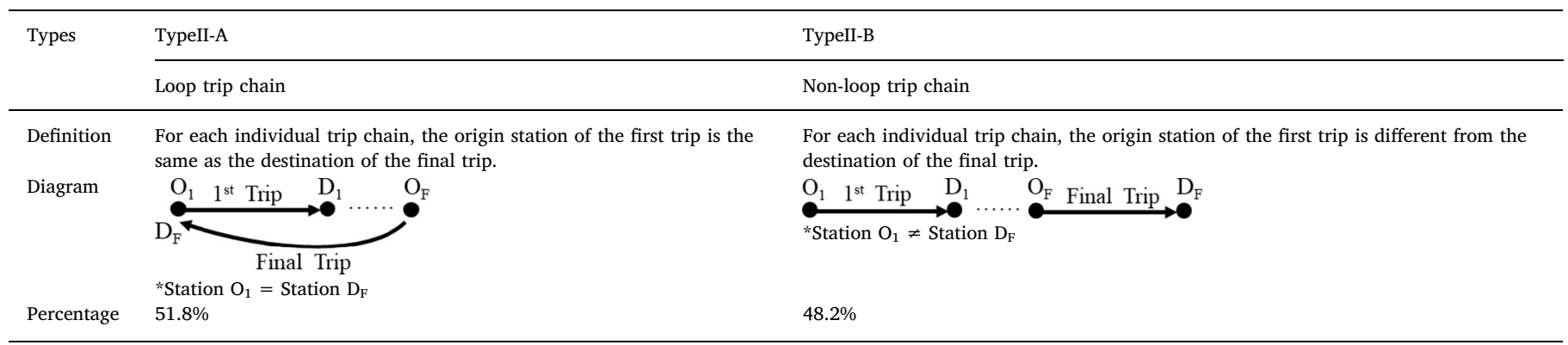


Table 3

Types of transition activities (weekdays).

\begin{tabular}{|c|c|c|}
\hline \multirow[t]{2}{*}{ Types } & TypeII-C & TypeII-D \\
\hline & Transfer at the same station & Transfer at different stations \\
\hline Definition & $\begin{array}{l}\text { A user ends the preceding trip at one station and starts the next trip from the } \\
\text { same station. }\end{array}$ & $\begin{array}{l}\text { A user ends the preceding trip at one station but starts the next trip from another } \\
\text { station. }\end{array}$ \\
\hline Diagram & Preceding trip Next trip & Preceding trip Next trip \\
\hline & $\begin{array}{lll}\mathrm{O}_{\mathrm{P}} & \mathrm{D}_{\mathrm{P}}\left(\mathrm{O}_{\mathrm{N}}\right) & \mathrm{D}_{\mathrm{N}}\end{array}$ & $\mathrm{D}_{\mathrm{P}} \quad \mathrm{O}_{\mathrm{N}}$ \\
\hline & لـ & لـ \\
\hline & Two consecutive trips & Two consecutive trips \\
\hline & ${ }^{*}$ Station DP $=$ Station ON & $*$ Station DP $\neq$ Station ON \\
\hline Percentage & $62.5 \%$ & $37.5 \%$ \\
\hline
\end{tabular}
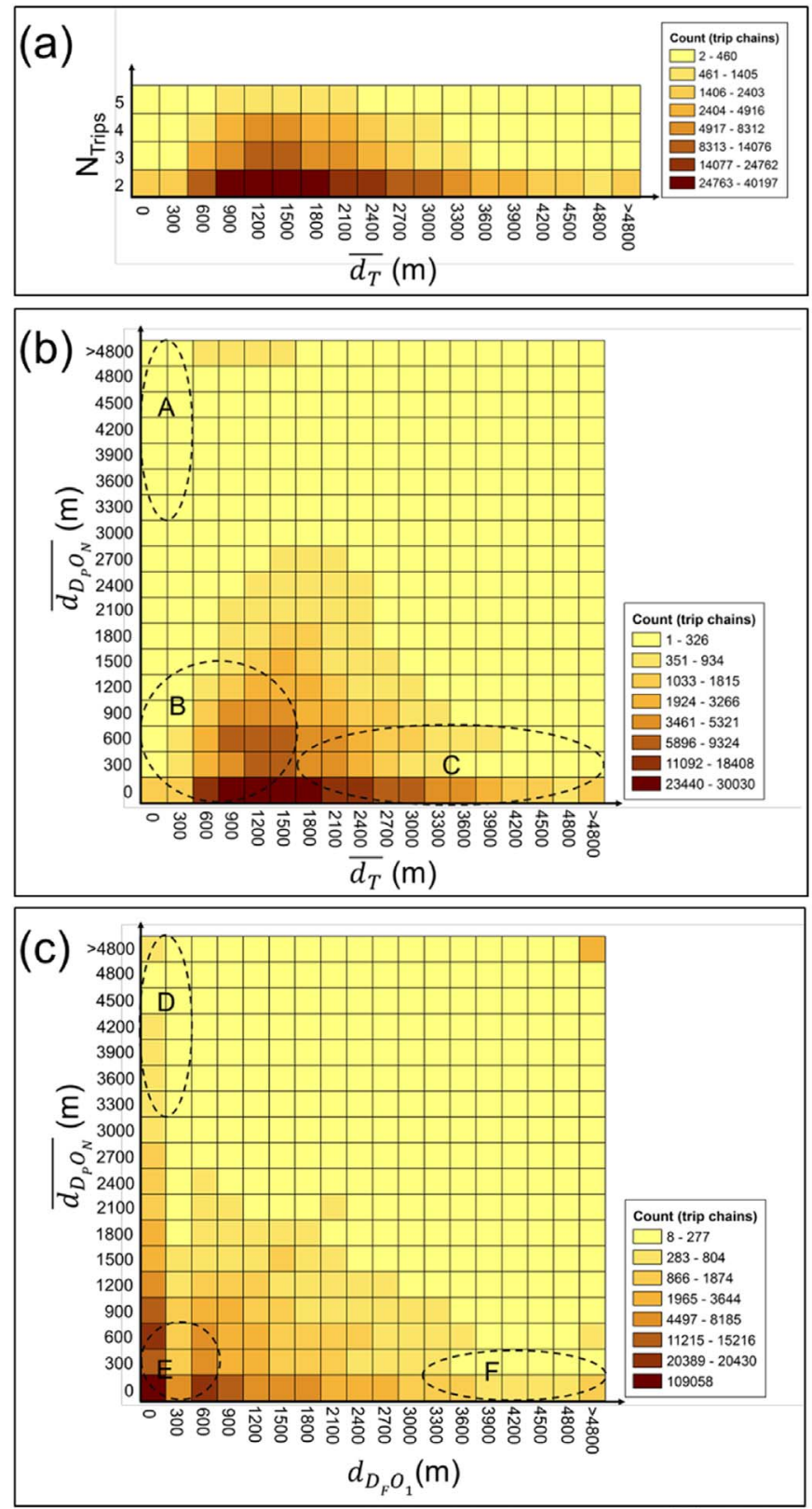

Fig. 7. Density plot of trip chain frequency. (a) The relation between $N_{\text {trip }}$ and $\overline{d_{T}}$; (b) the relation between $\overline{d_{D_{P} O_{N}}}$ and $\overline{d_{T}}$; (c) the relation between $\overline{d_{D_{P} O_{N}}}$ and $d_{D_{F}} O_{1}$. other.

Fig. 7(c) describes the relation between the average transfer distance per chain and the distance between the first origin and final destination per trip chain. The fact that both distance distributions are quite comparable, and that both distances are relatively small compared to trip lengths. Note that there are 109,058 trip chains for which distance $\overline{d_{D_{P} O_{N}}}$ and $\overline{d_{D_{P} O_{N}}}$ are 0 . This suggests that the majority of trip chains are more or less round trip chains (area E), even if in many cases he trip chain does not start and end at exactly the same station. Only few trip chains can be considered as real one way trip chains (area F). Interestingly, Fig. 7(c) shows no correlation between both distances, indicating that transfer distances do not necessarily depending on individual preferences, but rather appear to occur randomly, possibly depending on specific circumstances during the transfer. Finally, the lack of data in area A of Fig. 7(b) as well as in area D of Fig. 7(c) implies that public bikes are rarely used as a feeder mode to other public transport in our study area.

So far, we only looked at the trip and trip chain characteristics. We now turn our attention to the origins and destinations of the bikesharing trips. Fig. 8 shows the distribution of arrival times per destination station type, distinguishing between station types from which the trips were originating. As bike-sharing trips are mostly short (average duration is around 16 mins indicated by Zhang et al. (2017a, 2017b), departure time (h) is more or less the same as arrival time (h), therefore we only consider the latter.

Fig. 8 clearly shows a morning peak (7-9h) and evening peak (17-19 h), corresponding with typical commute time. Note that TypeII trip data also show a lunch peak for the residential destinations (presumably people that come home to have lunch). The observed patterns of bike-sharing trips imply that the majority of bike-sharing trips might relate to work, home, and shopping. In addition, there are a number of trips travelling between two stations with the same type (especially the residential), which can be explained by the fact that the residential stations are mostly located in front of the gate of residential communities, which may contain retail shops and groceries that could be destinations. This is a case of mixed using type of land use which cannot be avoided.

Fig. 9 describes transition activities between two consecutive trips within a trip chain, for TypeII-C (upper panel) and TypeII-D (lower panel) respectively. The $\mathrm{Y}$ axis shows when and where each user completed the preceding trip, and the $\mathrm{X}$ axis shows when and where the user started the next trip. Each cell shows the number of transition activities, the number of times between two consecutive trips within trip chains. Based on Fig. 9 (e.g. see the enlargement of one panel for more details), predominant patterns of individual transition activities have been observed and are summarized in Table 4. These predominant patterns suggest that users might use public bikes for going to work and home. TypeII-C depicts a user who transfers at the same station between 
Type I
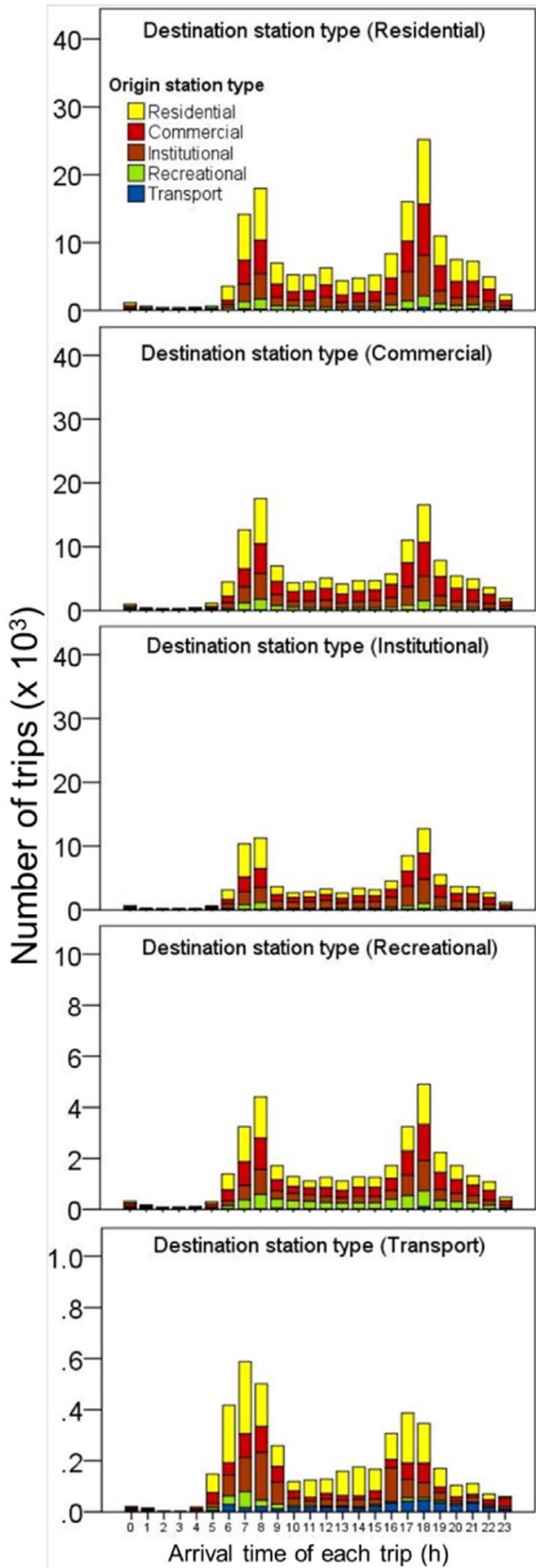

Type II
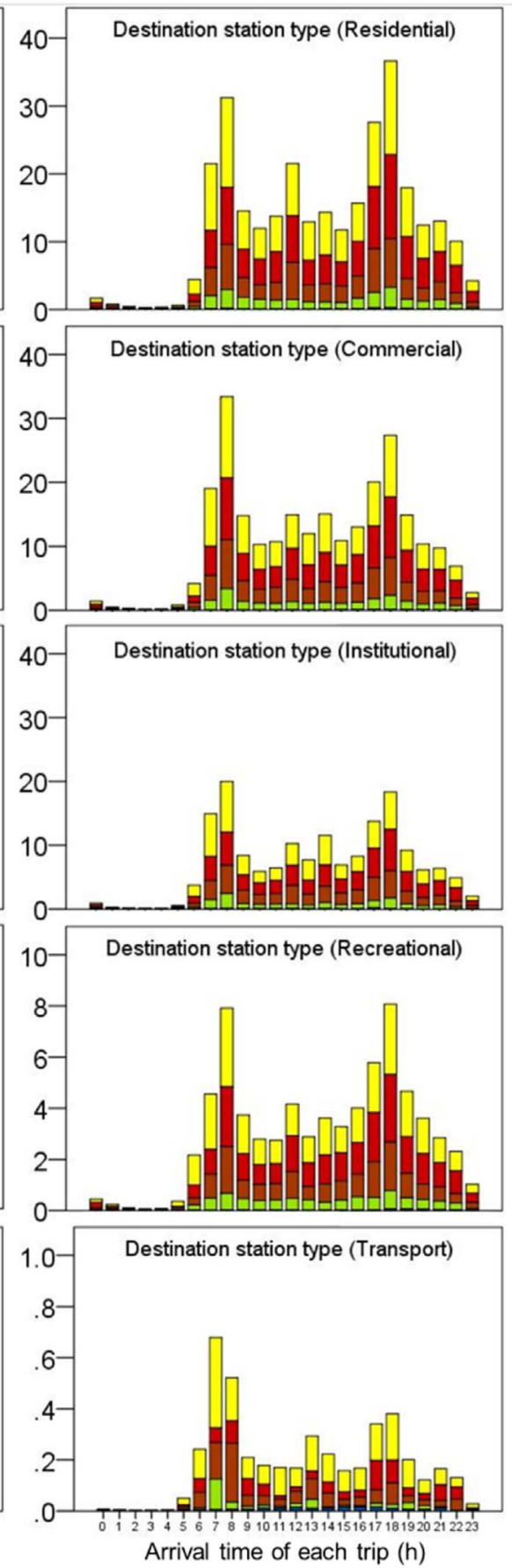

Fig. 8. Distribution function of arrival time and origin and destination locations of individual trips. 

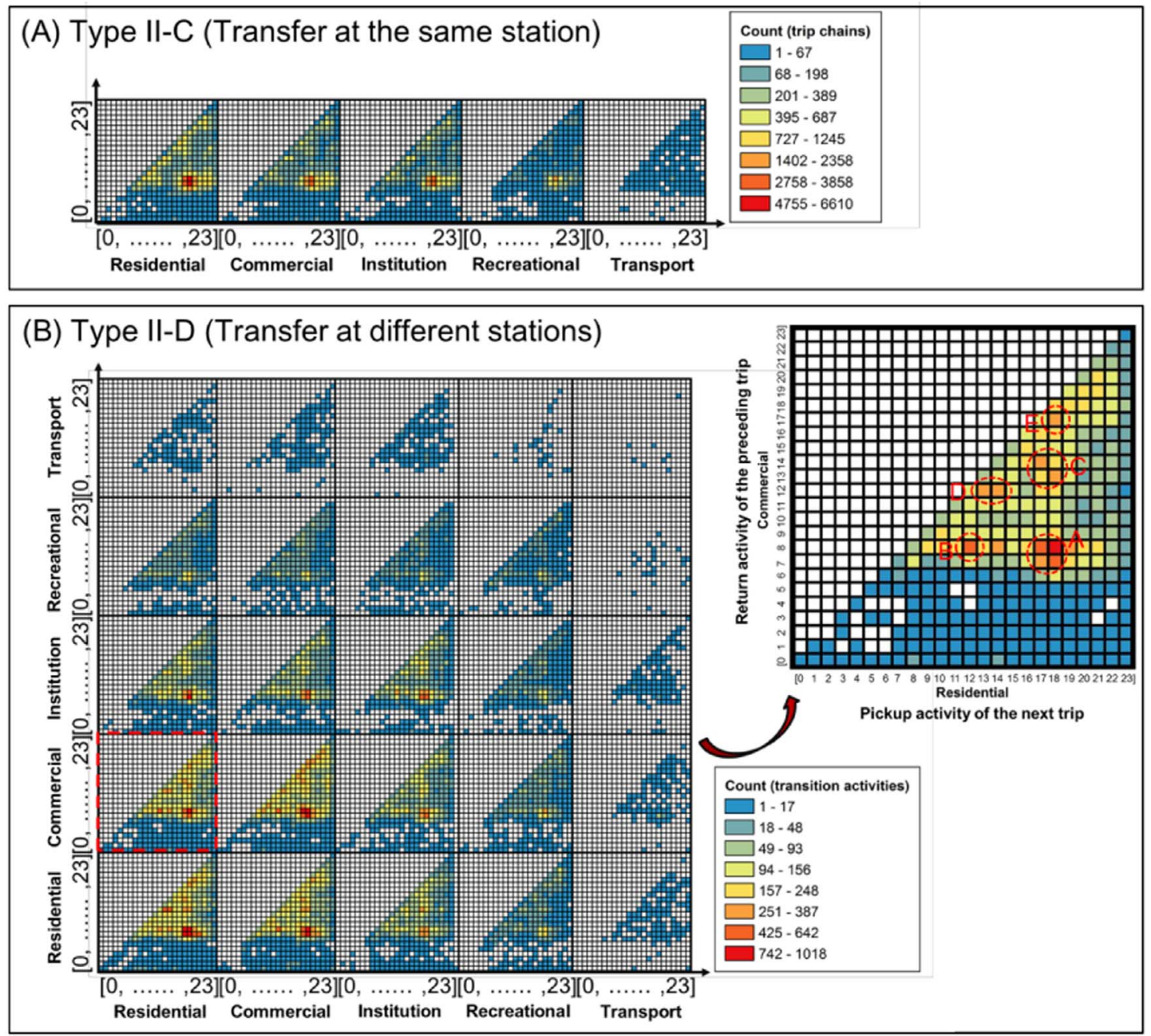

Fig. 9. Matrices of transition activities TypeII-C (upper panel) and TypeII-D (lower panel).

activities, incorporating the hourly pickup and drop-off activities and station type, to uncover the temporal patterns and potential purpose of bike-sharing usage.

Only a small fraction (4.5\%) of overall weekday trips start and end at the same station, which might be associated with recreational activities (physical exercises), or short-time activities (e.g. quick shopping). By far most trips are between different origin and destination stations, and about two thirds are part of a trip chain.

Our findings suggest that transfers during trip chains are often between nearby stations, suggesting public bikes are mainly used as the single transport mode, either for the short local movement that might substitute for walking, or for a long distance trip. The fact that people transfer between different stations might be related to the lack of bikes or slots at certain stations or may simply be a coincidence as the density of bike stations is quite high, and there are several stations to choose from when considering a new trip. Although most trip chains don't start and end at exactly the same station, most of those chains can be considered as round trip chains, because distances between start and end station are in general quite small, comparable with transfer distances between trips in the trip chains, and typically smaller than the trips themselves. In short, public bikes are mostly used as a transport mode by itself for relatively short distances, but in which users are quite flexible in choosing the origin and/or destination stations for all trips in the trip chain.

The primary patterns of bike-sharing usage can be observed from matrices of each type of trip chains and transition activities. In general, the findings suggest that user mainly used public bikes for commuting, and some users went home during lunch break. Moreover, some of the users show an after-work shopping activity.

Of course this study is not without limitation: firstly, we use station type to uncover the potential purpose of bike-sharing usage, shile users might come from or go to other places that are not close to the station. Actual travel purposes can only be done by on-site surveys, which is beyond the purpose of this study. Secondly, the period of trip chain (now fixed between 0:00 $\mathrm{h}$ to $23: 59 \mathrm{~h}$ ) is in reality of flexible as some people undertake nightly activities. However, these cases are relatively

Table 4

Dominant patterns of transition activity TypeII-C and TypeII-D.

Dominant pattern

(TypeII-C \& TypeII-D)
- The interval time is around 9-11 h, i.e. a user arrives at 7-9 a.m. and starts again at 5-7 p.m. (area A).

- The interval time is around 3-5 h, i.e. a user arrives at 8-9 a.m. and starts again at 12 p.m. (area B), or arrives at 1-2 p.m. and starts again at 5-7 p.m. (area C).

- The interval time is 1-2 h, i.e. a user arrives at 12 p.m. and starts again at 1-2 p.m. (area D), or a user arrives at 5-6 p.m. and starts again at 5-7 p.m. (area E). 

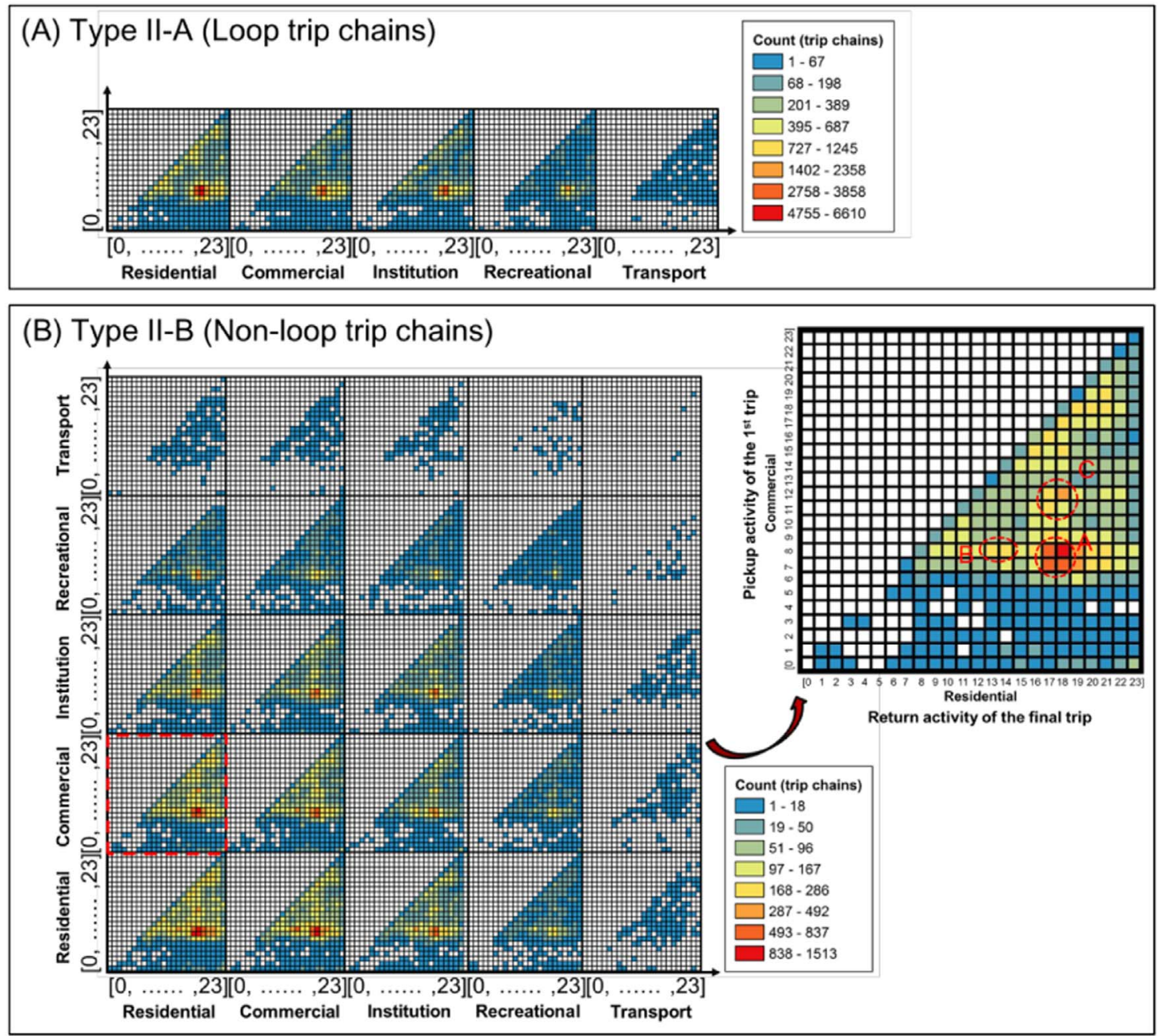

Fig. 10. Matrices of trip chains TypeII-A (upper panel) and TypeII-B (lower panel).

Table 5

Dominant patterns of bike-sharing trip chains TypeII-A and TypeII-B.

$\begin{aligned} & \text { Same pattern } \\ & \text { (TypeII-A \& } \\ & \text { TypeII-B) }\end{aligned}$
$\begin{aligned} & \text { Distinctive pattern } \\ & \text { (TypeII-B) }\end{aligned}$
trip at 5-7 p.m. within the same day (area A).
- Users start the first trip at 8-9 a.m. and end the final
trip at $1-3$ p.m. within the same day (area B);
- Users start the first trip at 11 a.m.-1 p.m. and end the
final trip at 5 p.m.-7 p.m. within the same day (area
C).

rare, and probably would not change the general results. We therefore believe that this study still provides a complete insight into how the bike-sharing system is used, in terms of both trips and activities. With reference to those methods and insights, urban planners, policy makers and researchers can also explore the patterns of trip chains and transition activities of other systems, which could be beneficial to improving the existing system.

\section{Funding source}

This work was supported by the China Scholarship Council (CSC) [No. 2011627129] and co-funded by the ITC Research Fund [No. 93002823]. The funders had no role in study design, data collection and analysis, decision to publish, or preparation of the manuscript.

\section{Acknowledgments}

We are grateful to the Transport Department of the Urban Planning and Design Institute of Zhongshan (China) for offering database and valuable help during fieldwork. We are also grateful for the valuable comments and suggestions from the Editor (Prof. Jean-Claude Thill) and two anonymous reviewers. We appreciate the helpful advice from Prof. Huang Zhengdong during the revision stage.

\section{References}

Ahillen, M., Mateo-Babiano, D., \& Corcoran, J. (2016). Dynamics of bike sharing in Washington, DC and Brisbane, Australia: Implications for policy and planning. International Journal of Sustainable Transportation, 10(5), 441-454. http://dx.doi.org/ 10.1080/15568318.2014.966933.

Bachand-Marleau, J., Lee, B., \& El-Geneidy, A. (2012). Better understanding of factors influencing likelihood of using shared bicycle systems and frequency of use. Transportation Research Record, 2314, 66-71. http://dx.doi.org/10.3141/2314-09.

Beecham, R., \& Wood, J. (2014). Exploring gendered cycling behaviours within a largescale behavioural data-set. Transportation Planning and Technology, 37(1), 83-97. http://dx.doi.org/10.1080/03081060.2013.844903.

Bordagaray, M., Dell'Olio, L., Fonzone, A., \& Ibeas, A. (2016). Capturing the conditions that introduce systematic variation in bike-sharing travel behavior using data mining techniques. Transportation Research Part C, 71, 231-248. http://dx.doi.org/10.1016/ j.trc.2016.07.009.

Bullock, C., Brereton, F., \& Bailey, S. (2017). The economic contribution of public bikeshare to the sustainability and efficient functioning of cities. Sustainable Cities and Society, 28, 76-87. http://dx.doi.org/10.1016/j.scs.2016.08.024.

Castillo-Manzano, J. I., Castro-Nuño, M., \& López-Valpuesta, L. (2015). Analyzing the transition from a public bicycle system to bicycle ownership: A complex relationship. Transportation Research Part D: Transport and Environment, 38, 15-26. http://dx.doi. org/10.1016/j.trd.2015.04.004. 
DeMaio, P. (2009). Bike-sharing: History, impacts, models of provision, and future. Public transportation. 12. Public transportation (pp. 16-). .

El-Assi, W., Salah Mahmoud, M., \& Nurul Habib, K. (2015). Effects of built environment and weather on bike sharing demand: A station level analysis of commercial bike sharing in Toronto. Transportation, 1-25. http://dx.doi.org/10.1007/s11116-0159669-z.

Faghih-Imani, A., \& Eluru, N. (2015). Analysing bicycle-sharing system user destination choice preferences: Chicago's Divvy system. Journal of Transport Geography, 44, 53-64. http://dx.doi.org/10.1016/j.jtrangeo.2015.03.005.

Faghih-Imani, A., \& Eluru, N. (2016a). Determining the role of bicycle sharing system infrastructure installation decision on usage: Case study of montreal BIXI system. Transportation Research Part A: Policy and Practice, 94, 685-698. http://dx.doi.org/10. 1016/j.tra.2016.10.024.

Faghih-Imani, A., \& Eluru, N. (2016b). Incorporating the impact of spatio-temporal interactions on bicycle sharing system demand: A case study of New York CitiBike system. Journal of Transport Geography, 54, 218-227. http://dx.doi.org/10.1016/j. jtrangeo.2016.06.008

Faghih-Imani, A., Eluru, N., El-Geneidy, A. M., Rabbat, M., \& Haq, U. (2014). How landuse and urban form impact bicycle flows: Evidence from the bicycle-sharing system (BIXI) in Montreal. Journal of Transport Geography, 41, 306-314. http://dx.doi.org/ 10.1016/j.jtrangeo.2014.01.013

Fishman, E. (2016). Bikeshare: A review of recent literature. Transport Reviews, 36(1), 92-113. http://dx.doi.org/10.1080/01441647.2015.1033036.

Fishman, E., Washington, S., \& Haworth, N. (2014). Bike share's impact on car use: Evidence from the United States, Great Britain, and Australia. Transportation Research Part D: Transport and Environment, 31, 13-20. http://dx.doi.org/10.1016/j.trd.2014. 05.013.

Fishman, E., Washington, S., \& Haworth, N. (2015). Bikeshare's impact on active travel: Evidence from the United States, Great Britain, and Australia. Journal of Transport \& Health, 2(2), 135-142. http://dx.doi.org/10.1016/j.jth.2015.03.004.

Fishman, E., Washington, S., Haworth, N., \& Mazzei, A. (2014). Barriers to bikesharing: An analysis from Melbourne and Brisbane. Journal of Transport Geography, 41, 325-337. http://dx.doi.org/10.1016/j.jtrangeo.2014.08.005.

Gonzalez, F., Melo-Riquelme, C., \& de Grange, L. (2016). A combined destination and route choice model for a bicycle sharing system. Transportation, 43(3), 407-423. http://dx.doi.org/10.1007/s11116-015-9581-6.

Jäppinen, S., Toivonen, T., \& Salonen, M. (2013). Modelling the potential effect of shared bicycles on public transport travel times in Greater Helsinki: An open data approach. Applied Geography, 43, 13-24. http://dx.doi.org/10.1016/j.apgeog.2013.05.010.

Jensen, P., Rouquier, J.-B., Ovtracht, N., \& Robardet, C. (2010). Characterizing the speed and paths of shared bicycle use in Lyon. Transportation Research Part D: Transport and Environment, 15(8), 522-524. http://dx.doi.org/10.1016/j.trd.2010.07.002.

Jiménez, P., Nogal, M., Caulfield, B., \& Pilla, F. (2016). Perceptually important points of mobility patterns to characterise bike sharing systems: The Dublin case. Journal of Transport Geography, 54, 228-239. http://dx.doi.org/10.1016/j.jtrangeo.2016.06. 010.

Kager, R., Bertolini, L., \& Te Brommelstroet, M. (2016). Characterisation of and reflections on the synergy of bicycles and public transport. Transportation Research Part A: Policy and Practice, 85, 208-219. http://dx.doi.org/10.1016/j.tra.2016.01.015.

Kaltenbrunner, A., Meza, R., Grivolla, J., Codina, J., \& Banchs, R. (2010). Urban cycles and mobility patterns: Exploring and predicting trends in a bicycle-based public transport system. Pervasive and Mobile Computing, 6(4), 455-466. http://dx.doi.org/ 10.1016/j.pmcj.2010.07.002.

Lathia, N., Ahmed, S., \& Capra, L. (2012). Measuring the impact of opening the London shared bicycle scheme to casual users. Transportation Research Part C, 22, 88-102. http://dx.doi.org/10.1016/j.trc.2011.12.004.

Martin, E. W., \& Shaheen, S. A. (2014). Evaluating public transit modal shift dynamics in response to bikesharing: A tale of two U.S. cities. Journal of Transport Geography, 41, 315-324. http://dx.doi.org/10.1016/j.jtrangeo.2014.06.026.

Mateo-Babiano, I., Bean, R., Corcoran, J., \& Pojani, D. (2016). How does our natural and built environment affect the use of bicycle sharing? Transportation Research Part A: Policy and Practice, 94, 295-307. http://dx.doi.org/10.1016/j.tra.2016.09.015.
Meddin, R., \& DeMaio, P. (2017). The bike-sharing blog. Retrieved from http://bikesharing.blogspot.com/.

Murphy, E., \& Usher, J. (2015). The role of bicycle-sharing in the city: Analysis of the Irish experience. International Journal of Sustainable Transportation, 9(2), 116-125. http:// dx.doi.org/10.1080/15568318.2012.748855.

Nikitas, A., Wallgren, P., \& Rexfelt, O. (2016). The paradox of public acceptance of bike sharing in Gothenburg. Proceedings of the Institution of Civil Engineers-Engineering Sustainability, 169(3), 101-113. http://dx.doi.org/10.1680/jensu.14.00070.

Oliveira, G. N., Sotomayor, J. L., Torchelsen, R. P., Silva, C. T., \& Comba, J. L. D. (2016). Visual analysis of bike-sharing systems. Computers \& Graphics, 60, 119-129. http:// dx.doi.org/10.1016/j.cag.2016.08.005.

O'Neil, P., \& Caulfield, B. (2012). Examining user behaviour on a shared bike scheme: the case of Dublin Bikes. Paper presented at the The 13th International Conference on Travel Behaviour Research, Toronto. http://hdl.handle.net/2262/68119.

Ricci, M. (2015). Bike sharing: A review of evidence on impacts and processes of implementation and operation. Research in Transportation Business \& Management, 15, 28-38. http://dx.doi.org/10.1016/j.rtbm.2015.03.003.

Shaheen, S., Guzman, S., \& Zhang, H. (2010). Bikesharing in Europe, the Americas, and Asia past, present, and future. Transportation Research Record, 2143, 159-167. http:// dx.doi.org/10.3141/2143-20.

Shaheen, S., Martin, E., Cohen, A. P., \& Finson, R. S. (2012). Public Bikesharing in North America: Early operator and user understanding. California: Retrieved from San José State University.

Shaheen, S., Zhang, H., Martin, E., \& Guzman, S. (2011). Hangzhou public bicycle: Understanding early adoption and behavioral response to bikesharing in Hangzhou, China. Transportation Research Record, 2247, 34-41. http://dx.doi.org/10.3141/ 2247-05.

Tang, Y., Pan, H., \& Shen, Q. (2011). Bike-sharing systems in Beijing, Shanghai, and Hangzhou and their impact on travel behavior. Paper presented at the Transportation Research Board 90th Annual Meeting, Washington DC. http://trid.trb.org/view.aspx? id $=1093278$.

Vogel, P., Greiser, T., \& Mattfeld, D. C. (2011). Understanding bike-sharing systems using data mining: Exploring activity patterns. Procedia - Social and Behavioral Sciences, 20 514-523. http://dx.doi.org/10.1016/j.sbspro.2011.08.058.

Wang, Z. G., Kong, Z., Xie, J. H., \& Yin, L. E. (2009). The 3rd generation of bike sharing systems in Europe: Programs and implications. Urban Transport of China, 7(4).

Wu, L., Zhi, Y., Sui, Z., \& Liu, Y. (2014). Intra-urban human mobility and activity transition: Evidence from social media check-in data. PLoS One, 9(5), e97010. http://dx. doi.org/10.1371/journal.pone.0097010.

Yang, R. R., \& Long, R. Y. (2016). Analysis of the influencing factors of the public willingness to participate in public bicycle projects and intervention strategies-A case study of Jiangsu Province, China. Sustainability, 8(4), 16. http://dx.doi.org/10.3390/ su8040349.

Zaltz Austwick, M., O'Brien, O., Strano, E., \& Viana, M. (2013). The structure of spatial networks and communities in bicycle sharing systems. PLoS One, 8(9), e74685. http://dx.doi.org/10.1371/journal.pone.0074685.

Zhang, L., Zhang, J., Duan, Z.-y., \& Bryde, D. (2015). Sustainable bike-sharing systems: Characteristics and commonalities across cases in urban China. Journal of Cleaner Production, 97, 124-133. http://dx.doi.org/10.1016/j.jclepro.2014.04.006.

Zhang, Y., Thomas, T., Brussel, M., \& van Maarseveen, M. (2017a). Exploring the impact of built environment factors on the use of public bikes at bike stations: Case study in Zhongshan, China. Journal of Transport Geography, 58, 59-70. http://dx.doi.org/10. 1016/j.jtrangeo.2016.11.014

Zhang, Y., Thomas, T., Brussel, M. J. G., \& van Maarseveen, M. F. A. M. (2017b). The characteristics of bike-sharing usage: Case study in Zhongshan, China. The International Journal of Transport Development and Integration, 1(2), 245-255.

Zhao, J., Wang, J., \& Deng, W. (2015). Exploring bikesharing travel time and trip chain by gender and day of the week. Transportation Research Part C, 58(Part B), 251-264. http://dx.doi.org/10.1016/j.trc.2015.01.030.

ZhongshanStatisticsBureau (2014). Zhongshan statistic yearbook 2014. Retrieved from http://www.zsda.gov.cn/plus/php_dq_zhishu.php. 